УДК 811.112 .2

DOI: 10.33184/YVDK-2021-04-30.55

Л.А. Пасечная (доц. ОГУ, г. Оренбург),

В.Е. Щербина (доц. ОГУ, г. Оренбург)

\title{
СЕМАНТИКА ГЛАГОЛА КАК СТРУКТУРООБРАЗУЮЩИЙ ФАКТОР НЕМЕЦКОГО ПРЕДЛОЖЕНИЯ
}

B статье рассмотрены валентностные типь объектных глаголов, которые имеют практическое значение для построения грамматически корректного предложения. $B$ результате анализа примеров из художественной литературы выявлены релевантные компоненты, определяющие валентность глаголов.

Ключевые слова: валентность, актант, объектные глаголь, субъектные глаголы, семантическая сочетаемость.

The article discusses the valence objects of object verbs, which are of practical importance for constructing a grammatically correct sentence. As a result of the analysis of examples from fiction, the relevant components that determine the valency of verbs were identified.

Keywords: valency, actant, object verbs, subjective verbs, semantic compatibility.

В процессе обучения немецкому языку важное значение имеет практический аспект построения грамматически корректного предложения. Даже хорошо успевающие студенты допускают в речи много ошибок,обусловленных валентностью глаголов. Чаще всего это наблюдается в семантической сочетаемости слов. Для студентов является трудностью различать сходные по значению слова, которые, однако, отличаются их синтаксическим окружением: kennen-wissen, warten-erwartenabwarten и т.д. Посредством валентностного анализа можно устранить или сократить вероятность таких ошибок. 
С.М. Кибардина выделяет среди всего множества глаголов две основные группы: субъектные и объектные глаголы [Кибардина 1988: 56]. Немецкие лингвисты О. Бехагель и Г. Хизе подобным образом разделяют глаголы на абсолютные или субъектные (т.е. не требующие объекта) и относительные или объективные (т.е. требующие объекта). К абсолютным глаголам относятся такие, которые не нуждаются в других объектах кроме подлежащего. При этом предложение остается грамматически корректным. К относительным же глаголам относятся такие, которые, помимо подлежащего нуждаются, по крайней мере, еще в одном объекте, чтобы предложение было грамматически верным. Субъект и объект рассматриваются как основные актанты глагола. От других актантов субъект и объект отличаются широтой своей семантики, конкретизируемой в зависимости от валентностного типа глагола. Субъект определяется как актант, называющий носителя состояния, производителя (источник) действия. Объект представляет собой актант, называющий предмет, на который направлено или с которым совершается действие. В результате этого действия он изменяется сам (возникает, уничтожается, изменяет свойства, состояние, форму, положение и другие признаки), изменяет свое отношение к действию, субъекту или другим участникам ситуации [Чубарова 2017: 119].

В данной статье на конкретных примерах из немецкой художественной литературы рассмотрены валентностные типы объектных глаголов.

К основным содержательным структурам объектных глаголов согласно выбранной нами классификации СМ. Кибардиной принадлежат следующие:

1. Субъект и объект существуют: субъект обладает объектом, выражает свое отношение к нему, совершает действие над объектом, объект при этом не изменяется или его изменение не существенно для обозначаемой ситуации;

2. Субъект воздействует на объект, в результате чего объект изменяется: изменяет свои признаки, свойства, состояния, положение, разрушается; возникает, исчезает;

3. Субъект и объект не изменяется в своей качественной определенности, изменяется отношение между ними: субъект 
отдает объект, лишается объекта, получает объект, субъект снабжает объектом кого/ что-либо.

Объектные глаголы в основном являются глаголами действия, прочие компоненты их значений аналогичны компонентам субъектных глаголов с той разницей, что определяющую роль играют признаки объекта. Наличие объекта увеличивает степень факультативности прочих актантов. Для большинства объектных глаголов характерно наличие более или менее обязательного в содержательном плане актанта с семантикой инструмента.

Глаголы, обозначающие существование субъекта и объекта.

Данная группа глаголов подразделяется на двух- и трехвалентные глаголы. К двухвалентным относятся глаголы обладания: besitzen, verfügen, halten, behalten, tragen, beherrschen, bestimmen:

Brauch' ich dir das zu sagen, der du so oft die Last getragen hast (F. Schiller);

Er ... beherrschte mit Bindung zusammen den Tisch (E.M. Remarque);

в том числе с объектом, называющим информацию, kennen, wissen, behaupten, denken, glauben, meinen:

denn er wusste, ein paar heiße Kinderhände bauten ihm die Brücke zu ihrem Herzen (S. Zweig); Ich glaubte ihr kein Wort (E.M. Remarque); Lenz behauptete, Karl wirke erzieherisch (E.M. Remarque),

с включенным отрицанием - entbehren, missen, vermissen:

Es schien, als hätten sie ihn gar nicht sonderlich vermisst ( $\mathrm{S}$. Zweig); „Das ist immer so, wenn man etwas lange entbehrt hat" (F. Schiller);

глаголы восприятия, подразделяющиеся в зависимости от соответствующего органа чувств на глаголы зрения - sehen, bemerken, betrachten, merken, mustern, übersehenи т.п.:

... und jetzt... merkte er erschreckt, dass er noch in den Kleidern stak; Beim Einsteigen erst bemerkte er, dass seine Karte für die Dritte Klasse galt (S .Zweig); Wir sehen glückliche Menschen, die wir nicht glücklich machen, und das ist unerträglich (F. Schiller);

Глаголы слуха - hören, horchen, lauschen, vernehmen и др.: 
Da hörte er hinter sich ein Kleid rauschen und eine Stimme leicht ärgerlich und mit affektiertem Akzent sagen (S. Zweig); Edgar gehorchte (die Mutter), ließ aber nicht ab, den Baron auszufragen; Er horchte angestrengt; ... es war die Frau meines Lehrers, die offenbar an der Tür gelauscht hatte (S. Zweig).

Сюда же примыкает несколько групп глаголов, в разной степени связанных с восприятием объекта: treffen, begegnen; entdecken, finden, stoßen; suchen, warten, empfangen и др.

Ich empfing voll Ruhe die Leute, erzählte ihnen allen die gleiche erdichtete Geschichte (S. Zweig);

Wo ich hintrete, begegnet mir eine Erscheinung, die mich aus aller Fassung bringt (F. Schiller); Ich stellte den Spirituskocher auf die Bank und suchte die Dose mit Kaffee (E.M. Remarque).

Семантика объекта определяется семантикой глагола, для большинства данных глаголов типичен распространитель, называющий местоположение субъекта или объекта, ср.:

Ich habe eine Axt in der Mappe (M. Frisch); ... und ich halte sie in den Armen... (E.M. Remarque); Er beobachtete den Unmut in Boikes Gesicht (R. Schuder); Ich habe gestern irgendwo hier den Namen gehört (E.M. Remarque); ...ich spüre plötzlich Tränen hinter meinen Augen (E.M. Remarque).

Глаголы восприятия могут реализовать факультативный актант, называющий орган чувств:

... aber mit Augen gesehen habe ich es nie, wie das Geld arbeitet (M. Frisch); Schlangen hören mit der Haut (E.M. Remarque).

Двухвалентными являются глаголы отношения субъекта к объекту, включающие в семантику компонент положительного или отрицательного отношения: achten, bedauern, bereuen, bewundern, hassen, lieben, verehren, ignorieren, meiden, verzichten и др.:

Kein Mensch wusste, ob er den, den er jetzt bedauerte...; ich hasste dieses ganze Gerede vom Einswerden in der Liebe; Ich sah ihr Gesicht und verzichtete auf jeden Widerstand... (E.M. Remarque); ... dass ich auf die Musik kaum achtete... (F. Schiller).

Глаголы betrachten, bezeichnen, finden, halten, schätzen ит.п. имеют третий актант с призначной семантикой:

Ich finde sie immerhin schön, diese Art von Musik (M. Frisch); Für einen Wahnsinnigen, für einen Trunkenen halten sie ihn (S. Zweig); Kalt und neugierig betrachtete ich es (E.M. Remarque); Man 
kann hier schlecht ausreißen, und fromme Leute bezeichnen so was leicht als Schändung heiliger Stätten (E.M. Remarque).

Глаголы действия над объектом, обозначающие различные действия (bearbeiten, behandeln; beizen, filzen, scheuern, waschen, wischen, essen, trinken, kauern, schlürfen, rauchen, messen, prüfen, untersuchen, bedenken, denken, sinnen, überlegen ит.п.), в зависимости от своей семантики могут реализовывать факультативный актант - инструмент, ср.:

Im Kriege hast du mit meinem Löffel Erbsensuppe gegessen... (E.M. Remarque); Wir werden deine Flosse mit Alkohol waschen... (E.M. Remarque); в большинстве случаев встречаются с двумя актантами:

... er trank en paar Glaeser Champagner dazwischen. (S. Zweig); „Schön“, sagte Pat und kauerte sich in die Ecke der Fensterbank (E.M. Remarque); Der Russe rauchte eine Zigarette nach der andern (E.M. Remarque).

У нескольких групп глаголов в качестве инструмента всегда или преимущественно предполагается часть тела субъекта: berühren, küssen, streicheln, tätscheln, schlagen, stoßen, treten и т.n.:

Bärlach berührte mit dem Fuß die unbewegliche Masse vor ihm (F. Dürrenmatt); Er schlug sie wieder. Diesmal mit dem Handrücken (J.R. Becher); Sie haben ihn mit Steifeln getreten (M. Frisch); ... und dann plötzlich den Tiger, der mit seinen gebleckten Sähnen aus dem Dschungel vorsprang und dem Elefanten die Pranke in den Rüssel schlug (S. Zweig); ... küsste sie ... mit den Lippen von den feinen Fingerspitzen bis hinauf zum Handgelenk... (S. Zweig).

Ряд глаголов действия над одушевленным объектом включает в семантику оценочный компонент: betreuen, betrügen, drollen, erziehen, liebkosen, quälen, überlisten, verführen, verraten:

Und nun quälen sie ihn mit Schuldenscheinen und hetzen ihn zu Tode (S. Zweig); „Willst du zum Deserteur werden? Die Brüderschaft verraten?" (E.M. Remarque).

Глаголы benutzen, gebrauchen, missbrauchen, nutzen, verwenden имеют актант с семантикой цели:

Ich nutze die Gelegenheit, um mich umzublicken... (G. Radtke); Die längste Zeit verwandte er auf die Pflege seiner wießblonden Lockerpracht...(G. Radtke); 
cp. behüten, bewahren, schützen, verteidigen:

Dann verteidigte er den Hof gegen die Landjäger (H. Fallada).

Глаголы, обозначающие изменение объекта. Данные глаголы называют различные качественные и количественные изменения, изменения состояний, свойств, формы объекта: ändern, verwandeln, berichtigen, beschönigen, bessern, mehren, erhitzen, kühlen, nassen, trocknen, weichen, öffnen, schließen, bleichen, biegen, glätten:

... und dessen Arbeitserfolge sich sofort in Form der Provision zu Bargeld verwandelten (F. Kafka); Aber dann ging natürlich wie immer das Dienstmädchen festen Schrittes zur Tür und öffnete (F. Kafka); Sie schrie herein, wenn jemand die Tür öffnete (E.M. Remarque); Ich glättete die Scheine und steckte sie ein (E.M. Remarque);

Разрушение объекта: brechen, erbrennen, ermorden, erschlagen:

... hätte man glauben können, er habe sich soeben die Sohle verbrannt (F. Kafka); O mein Salgar, warum hast du meinen Bruder erschlagen? (F. Schiller).

Аналогично субъектным глаголам они могут иметь факультативные актанты начальной и конечной фазы изменения, но реализуют их значительно реже, ср.:

Er verwandelt unser Land in eine Wüste! (R. Schuder), редко реализуется актант с семантикой инструмента:

Mit einer Axt hat er Sie erschlagen, als ich im Wald war (M. Frisch).

Выделяются глаголы изменения эмоционального состояния объекта - лица, несколько чаще реализующий третий актант, который обычно имеет связь с субъектом: Den erschreckt auf die Uhr Starrenden beruhigte sie mit der Mitteilung, dass... (R. Schickele); Wir beruhigen ihn mit einem Doppelkümmel (E.M. Remarque).

Изменение объекта обозначает глагол machen, имеющий третий актант с семантикой признака, приобретаемого объектом:

Den halben Sonntag machte ich im Keller mit Petrolium und Schmiergelleinendie alte Dampfmaschine wieder einmal ansehlicher (G. Radtke); Bärlachsnachlässige Art machte Tschanz wild (F. Dürrenmatt). 
Глаголы изменения положения объекта (fahren, führen, rollen, schicken, schieben, tragen, verschieben, werfen, ziehen и др.) имеют и пространственные актанты, но реализуют их и их сочетания значительно реже:

Mit gefälschten Durchreisepapieren verschieben sie jede Woche acht Anhänger mit Brettern und anderem Schnittholz aus der DDR nach Westberlin (G. Radtke);

У объектных глаголов чаще встречается актант с семантикой конечной точки, но данный актант может иметь и семантику адресата:

... das einzige, was ich wissen musste: ob ich ihr das Kissen unter den Kopf schieben oder sie flach hinlegen sollte (E.M. Remarque); Arnold schickte die Krieger nach Hause... (R. Schuder); Ich habe ihn geschickt, um Holzwolle aufzutreiben (M. Frisch); Ich habe ihn nicht zum Kaiser geschickt! (R. Schuder); Sie führte mich über einen kleinen Vorplatz und öffnete dann eine Zimmertür. Er taumelte in die Arme der Köchin und rollte, umschlungen von ihr, zur Seite (E.M. Remarque).

B результате использования некоторыми глаголами действия над объектом валентностной структуры движения объекта возникает одна из промежуточных зон внутри поля объектных глаголов, ср.:

Ich schlug ihn zu Boden (P. Hacks); Sie stößt ihn in die Werkstatt (E.M. Remarque); Der Soldat schlägt ihm das Geld aus der Hand (M. Frisch); Mit einem alten Mappen wischte er die Öllachen vom Tisch (G. Radtke).

$\mathrm{K}$ глаголам созидания относятся machen, schaffen и ряд более конкретных глаголов, различающихся по семантике объекта и по способу его изготовления: bauen, drucken, erzeugen, graben, kochen, mauern, schreiben, spielen, sticken, zeichnen. Данные глаголы могут иметь актант, называющий материал, из которого создается объект, ср.:

Särge macht man aus Eiche, Tanne, Mahagonie furniert (E.M. Remarque), и актант с семантикой инструмента:

Ich koche auf meinem Spirituskocher Kaffee... (E.M. Remarque), но в большинстве случаев они встречаются только с двумя основными актантами: 
Jemand hatte da etwas gezeichnet (F. Kafka); Und so setzten sie sich zum Tisch und schrieben drei Entschuldigungsbriefe... (E.M. Remarque).

Глаголы с событийным объектом подразделяются на глаголы со значением совершения события (erregen, verschulden, verursachen, beginnen, vollenden, machen, tun и т.п.):

Und die alte Mutter sollte nun vielleicht Geld verdienen, die an Asthma litt, der eine Wanderung durch die Wohnung schon Anstrengung verursachte... (F. Kafka); Unter dem tue ich es jetzt nicht mehr... (E.M. Remarque);

И глаголы, обозначающие присутствие одушевленного объекта при событии (bestehen, erleben, verschmerzen, genießen, feiern, и др.):

Ich selbst habe merkwürdige Heilungen erlebt... (E.M. Remarque); Hast du Pat gesagt, dass wir unser eintägiges Jubiläum als Taxichauffeure feiern? (E.M. Remarque)

Выделяются также глаголы с дополнительными семантическими компонентами (wiederholen, pflegen, übertreiben, sich beteiligen):

... die Eltern, die niemals früher Zimmer vermietet hatten und deshalb die Höflichkeit gegen die Zimmerherren übertrieben, wagten gar nicht, sich auf ihre eigenen Sessel zu setzen... (F. Kafka); Sogar Erna Bönig in ihrem Drachenkimono beteiligte sich an dieser Orgie platonischer Mütterlichkeit (E.M. Remarque).

Глаголы, обозначающие изменение между субъектом и объектом. Большинство таких глаголов имеет три обязательных актанта, семантика третьего актанта определяется типом глагола. Проявляются также свойства глаголов движения.

У глаголов передачи объекта (geben, bieten, liefern, reichen; schenken, vermachen; verkaufen; leihen; bereiten, opfern, widmen) третий актант называет адресата, который может быть выражен как направление:

Einige Weiber... gaben ihr Wasser (F. Jung); Dann gibt er den Kugelschreiber zurück an Elsa (M. Frisch).

Возможны другие пространственные актанты:

Maresch reichte seinen Dienstausweis durch den Spalt in der Tür (G. Radtke). 
Частный случай передачи объекта представляют собой глаголы передачи информации vermitteln, verständigen, telegraphieren, zeigen, weisen, winken:

„Es ist genau so, Schwester“ - ich winkte der Stationsschwester...; Ich zeigte ihr die Medikamente durch die Tür (E.M. Remarque).

В разной степени эти свойства присущи глаголам речи sagen, berichten, erklären, erzählen, versprechen:

Ich habe dem Mädchen ausdrücklich gesagt, Sie sollen im Flur draußen warten (M. Frisch); Mit Eifer berichtet der junge Mann ihm von Paris (R. Schuder); Der Polizeiinspektor hat ihm einmal drei Monate lang seinen Besuch versprochen.. (H. Fallada); „Ich warte!“ sagte Rückert in die Stille (G. Radtke).

Два актанта имеют глаголы лишения объекта, обозначающие непроизвольные действия verlieren, verschlampen, vergessen, verlernen, versäumen:

... entweder verliere der Wagen zwanzig Kilometer an Geschwindigkeit oder er verwandele sich in ein Flugzeug (E.M. Remarque); Wie würde denn Gregor sonst einen Zug versäumen! (F. Kafka); Nie werde ich sie vergessen... (F. Schiller)

У глаголов получения объекта (bekommen, erhalten, nehmen, empfangen, gewinnen, verdienen, kaufen, mieten, erfahren и др.) третий актант с семантикой источника реализуется реже, чем адресат у глаголов передачи объекта, что объясняется его меньшей коммуникативной значимостью:

Er hat den Befehl von Eduard erhalten...(E.M. Remarque); Er nimmt ein Foto vom Schreibtisch (M. Frisch); Von mir erfährt auch der Staatsanwalt kein Wort! (G. Radtke).

Данный актант исключают глаголы, означающие насильственное овладение объектом (besetzen, besiegen, erobern, okkupieren и т.п.):

„Dir wird das Hallo schon vergehen“, schmunzelte Gottfried und eroberte eine Bratpfanne; Du hast damit souverän die Zeit besiegt und lebst doppelt,, (E.M. Remarque).

Глаголы ergreifen, fassen, greifen, haschen, packen выделяются способностью к «раздвоению» субъекта и объекта:

Und dann packte der Alte Fifi mit seiner Tatze an der Schulter...(K. Edschmid); Er hat das Gesangbuch in der Hand. Nun fasst er es bei beiden Deckeln... (H. Fallada). 
Глаголы ersetzen, tauschen относятся к глаголам передачи и получения объекта, имеют четыре актанта:

Ich tauschte mit ihm einen Oberstleutnant gegen zwei Majore (E.M. Remarque); Alle Geschenke, alle Gefälligkeiten der Welt ersetzen nicht einen Augenblick Vergnügen an sich selbst (F. Schiller).

Трехвалентные глаголы придания объекта соотносятся по своим семантическим и формальным признакам с глаголами передачи объекта, действия над объектом и изменения объекта; некоторые из них включают актант, называющий придаваемый объект, в свою семантику, ср.: versehen, versorgen; schmücken; bedecken, bewaffnen, krönen, verglassen, vergolden; lehren, nennen, segnen, beschuldigen:

Frau Kroll hat mich mit belegten Bröten bis Berlin versehen (E.M. Remarque); Hatte nur ganz in der Nähe dieses Delikatessgeschäft verglast (W. Schnurre); Der Arzt bedeckte die Wunden mit Tampons und klebte Heftpflasterstreifen darüber (E.M. Remarque).

Наряду с рассмотренными типами объектных глаголов выделяется несколько групп глаголов с более сложными свойствами, соотносимых одновременно с несколькими содержательными структурами, имеющих различные формы объекта: helfen, stören, hindern; drohen, belasten, erpressen; глаголы, связанные с глаголами речи: danken, gratulieren, grüssen, warnen, tadeln; bejahen, bezeigen, konstatieren, и глаголы типа beantragen, berechtigen, veranlassen; befehlen, erlauben, verzeihen:

Er nickte mir zu und half der jungen Spanierin behutsam und zart die Treppe hinauf; Ich half dem Mädchen in den Mantel; (E.M. Remarque); ... und seine Entfernung drohte in ihr ganzes Wesen eine Lücke zu reißen, die nicht wieder ausgefüllt werden konnte (F. Schiller); Er ließ vielmehr unsern Freund nicht ausreden, widersprach ihm eifrig und tadelte ihn, dass er einen Meuchelmörder in Schutz nehme (F. Schiller); ... endlich gestand er mir auch mit Schüchternheit, was sie ihm Rir kleine Vertraulichkeiten erlaubt... (F. Schiller).

Таким образом, основой определения валентности глагола может служить анализ его лексического значения, который позволил выделить в семантике глагола компоненты, релевантные для его валентности. 
Двухвалентными являются объектные глаголы, обозначающие изменение формы субъекта, глаголы, выделяющие внешние признаки существования и с атрибутивной валентностью.

Итак, двухвалентными являются объектные глаголы:

- обозначающие лишения объекта путем непроизвольных действий;

- обозначающие получение объекта;

- называющие различные качественные и количественные изменения, изменения состояния, свойств, формы объекта;

- обозначающие отношения субъекта к объекту, включающие в семантику компонент положительного и отрицательного отношения.

Трехвалентными являются объектные глаголы, обозначающие изменения положения субъекта в пространстве:

- обозначающие передачу объекта;

- обозначающие изменение эмоционального состояния объекта - лица;

- действия над объектом, обозначающие различные действия.

Четырехвалентными являются объектные глаголы, обозначающие взаимозаменяемость субъекта и объекта.

Четкое представление о степени обязательности реализации факультативных актантов поможет студентам избежать ошибок в речи и грамматически корректно строить предложения.

\section{ЛИТЕРАТУРА}

1. Кибардина, С. М. Валентность немецких глаголов [Текст]: дис. док.филол. наук / С.М. Кибардина. Вологда, 1988. - 123 с.

2. Чубарова, H. А. Глаголы с атрибутивной валентностью в современном немецком языке [Электронный ресурс] / Н.А. Чубарова // Известия волгоградского государственного педагогического университета. Филологические науки. - 2017. № 4. - C. 118-121. Режим доступа:

https://cyberleninka.ru/article/n/glagoly-satributivnoy-valentnostyu-v-sovremennomnemetskom-yazyke/viewer

(C) Пасечная Л.А., Щербина В.Е, 2021 г. 